\title{
The Impact of Financial Hoarding on Economic Growth in China
}

\author{
Yizheng Fu, Zhifang Su * and Qianqian Guo
}

check for updates

Citation: Fu, Y.; Su, Z.; Guo, Q. The Impact of Financial Hoarding on

Economic Growth in China. Sustainability 2021, 13, 8434. https:// doi.org/10.3390/su13158434

Academic Editors:

Domingo Ribeiro-Soriano and

Andrea Rey-Martí

Received: 10 June 2021

Accepted: 27 July 2021

Published: 28 July 2021

Publisher's Note: MDPI stays neutral with regard to jurisdictional claims in published maps and institutional affiliations.

Copyright: (c) 2021 by the authors. Licensee MDPI, Basel, Switzerland. This article is an open access article distributed under the terms and conditions of the Creative Commons Attribution (CC BY) license (https:// creativecommons.org/licenses/by/ $4.0 /)$.
College of Economics and Finance, Huaqiao University, Quanzhou 362021, China; 18011020004@stu.hqu.edu.cn (Y.F.); 20011020003@stu.hqu.edu.cn (Q.G.)

* Correspondence: suzufine@hqu.edu.cn; Tel.: +86-0595-22690021

\begin{abstract}
In recent years, more and more funds circulate internally in the financial field, which is called "financial hoarding". After calculations, the scale of China's financial hoarding was 242,178 billion yuan in the first quarter of 2003 and jumped to 1,801,706 billion yuan in the fourth quarter of 2016, which increased by nearly 7.4 times in the past 14 years and accelerated after 2014. The phenomenon that large amounts of money deviate from the real economy to virtual economy is called "shift from real economy to virtual economy". The large scale of financial hoarding will inevitably influence the economic growth in China. Does financial hoarding promote or inhibit the economy? Does the relationship change with the economic growth rate? To address this issue, this paper first provided theoretical analysis of the relationship between financial hoarding and economic growth. Then, it used the data of the first quarter of 2003 through the fourth quarter of 2016 in China for empirical analysis. The results revealed two facts. Firstly, the simultaneous equations model showed that financial hoarding and economic growth promote each other in the long run and financial hoarding can be conducive to economic growth. Secondly, the MS-VAR model showed that the relationship between financial hoarding and economic growth changed with the economic growth rate. In addition, financial hoarding had a positive effect on the economic growth under both medium and high economic growth regimes, but to a greater extent in high economic growth regimes.
\end{abstract}

Keywords: financial hoarding; economic growth; shift from real economy to virtual economy; simultaneous equation model; Markov switching model

\section{Introduction}

China is a country with a tradition of a high savings rate, and, therefore, there is a lot of cash hoarding. With the development of the financial market, residents can invest in stocks, bonds, and other financial assets to obtain higher returns than those of savings, or they can maintain and increase the value of assets by investing in real estate properties, which are about to increase in price. Thus, cash holding gradually transforms into financial hoarding. Since the 2008 financial crisis, the central bank has created numerous monetary policies to stimulate economic development. The rising money supply should reduce the market interest rate and the cost of investment for enterprises. However, the reality is that, with several policies of reducing interest rates, the situation of high interest rate has not yet improved. Enterprises still face difficult financing problems, especially the medium and small-sized enterprises. The deterioration of a real economy environment makes enterprises choose to invest in financial assets such as stocks, so that the money flows into the financial sector. The funds constantly flow out from the real economy, leading to the "hollowing out" of the real industry. This phenomenon is called "shift from real economy to virtual economy". Meanwhile, a large amount of funds flows into the virtual economy, which results in sharp fluctuations in the stock market, high price of real estate, and other serious impacts on the economy. The relationship between finance and economy has gradually become a problem for people from all fields. 
In the long-term research, money was regarded as neutral. Moreover, the change in the stock of money only causes fluctuations of commodity prices without any effect on the real economic output. Until the Swedish economist Wicksell [1] proposed the non-neutrality of money, it was found that the change of interest rate would affect the level of savings and investment, and ultimately the real economic output changes. With the development of research, Binswanger [2] found that U.S. economic growth deviated from the development of the stock market. That is, when the real economy does not grow or deflate, the financial market develops rapidly. In order to explain this phenomenon, Binswanger proposed the theory of "financial hoarding", which is that the funds only circulate in the field of finance without affecting real economy activities.

With the growth of China's economy and the development of finance, there is no doubt that more and more money will circulate in the financial sectors without going into the real economy. Though there are some articles that have discussed the relationship between finance and economy, there are few articles that use the theory of financial hoarding and study the relationship between financial hoarding and economic growth directly. This paper tries to use the perspective of financial hoarding to explore the relationship between financial hoarding and economic growth in China directly. Does financial hoarding promote or inhibit the economy? Recently, China has entered a new stage of development, and the economic growth rate has changed. Does the relationship change with the economic growth rate?

In order to study the relationship between financial hoarding and economic growth in China, this research conducts a series of analyses. Specially, this research takes the situation that China's economic growth rate changes and the rapid development of financial market into accord, so that this study can give some suggestions to create a healthy environment for economic and financial development.

This study makes the following contributions to the literature. First, with the soaring growth rate, the financial hoarding of China achieves large-scale. As large amounts of money deviate from the real economy, it will inevitably influence the economic growth in China. However, there is still no research that focuses on the relationship between financial hoarding and economic growth directly. It is urgent to consider whether financial hoarding is promoting or hindering the economic growth. This study not only analyzes the relationship between financial hoarding and economic growth in theoretical study, but also in empirical study. Secondly, influenced by the international market, China's economy enters into a "new normal" stage. Does the relationship between financial hoarding and economic growth change with the speed of economic development? In order to study this problem, the Markov switching vector autoregressions (MS-VAR) model is used to analyze the dynamic relationship between financial hoarding and economic growth in different economic growth regimes. The research shows that in both medium and high economic growth regimes, financial hoarding has a positive effect on the economic growth, but the degree of influence is different. Thirdly, this study fits the actual situation, and can give suggestions to the regulation of China's financial hoarding and help to create a healthy environment to promote economic growth.

The paper is structured as follows. Section 2 is a literature review. Section 3 is materials and methods. This section puts forward the theoretical analysis and research hypothesis on the mutual relationship between financial hoarding and economic growth. Based on the hypothesis, the methodology and data used in the empirical analysis is proposed. Section 4 reports the empirical results and analyzes the empirical results of simultaneous equations model and the Markov switching vector autoregressions model. Section 5 discusses the empirical results and gives some suggestions. Section 6 is the conclusion.

\section{Literature Review}

Finance is an important factor that will affect economic development. Studying the relationship between finance and economic growth is one of the hot topics in the economic research area. 
In early research, scholars believed the money was neutral. The change of monetary aggregate only reduces fluctuations of commodity prices without any effect on the real economic growth. However, with the development of research, scholars changed their opinions. Swedish economist Wicksell [1] holds that the change of interest rate would affect the level of savings and investment, and ultimately affect the real economic growth, which is called the non-neutrality of money. Binswanger [2] found that U.S. economic growth deviated from the development of the stock market and proposed the theory of financial hoarding to explain the phenomenon. This theory gives a new interpretation of the relationship between financial market development and economic growth. With the development of the financial market, there is no doubt that more and more money will be hoarded in the financial market without flow into the real economic market. Scholars put forward various theories and models to explain the emerging phenomenon in real economy. Andresen [3] proposed a continuous circuit model to critique the Post Keynesian model of hoarding. Nizam et al. [4] hold that there is a threshold effect of the financial inclusivenessgrowth nexus, which means that financial inclusiveness exhibits a non-monotonic positive relation with economic growth. Recently, scholars have found that there is a significant correlation between finance, trade openness, human capital, population policies, and other factors on economic growth [5-11].

China is a country with a tradition of a high savings rate. With the development of the financial market, there are bonds, stocks, futures, options, and other financial assets, and people have more financial products they can choose to invest in. Since the reform and opening up, the economy of China has developed rapidly. China has created a remarkable economic performance, and particular problems with the economic growth arose. In the process of exploring the relationship between China's economy and finance, a large number of scholars have carried out research [12,13]. Recently, researchers used the concept of financial hoarding to explain some phenomena in China. There is a long-existing mystery called "the mystery of Chinese currency". It talks about the contradictory phenomenon of excess money supply and low inflation in China. This part of funds is likely to flow into the financial virtual economy and become part of financial hoarding. Zhu [14] proved the existence of financial hoarding phenomenon in China and calculated financial hoarding scale in China. Ren [15] holds that the stock market played an important role in absorbing extra currency supply. The large amount of financial hoarding has become an important factor in affecting the financial asset price volatility. Ma and Song [16] found that there is a long-term equilibrium relationship between China's financial asset price volatility, financial hoarding and hot money. Hot money tends to enter the stock market, while financial hoarding is willing to enter into the real estate market. At the same time, financial hoarding changes the regulation effect of traditional monetary policies. It is more difficult for the central bank to stimulate the real economic output and influence the price level by regulating the money supply. Ma and $\mathrm{Xu}$ [17] proposed that due to the existence of financial hoarding, both price-based monetary policy and quantitative monetary policy are weakened. With the financial sector playing a more important role in economic activities than ever before, the relationship between savings, investment, new money supply, and economic growth becomes more complex. Chen and Zhang [18] study the relationship between financial development and economic growth from the perspective of Polarization Theory and respond to the theory of "financial cellar".

The above research showed that the amount of money beyond the currency circulation increases, which will cause changes in the relationship between supply, real economy investment, price level, and regulation policy. However, the existing research mainly studied the relationship between economic growth and the level of financial development. It rarely touched upon the area of studies from the perspective of financial hoarding. There is no doubt that financial hoarding will influence the economic growth, but researchers just used the theory of financial hoarding to analyze some phenomena in the financial market, without empirical analysis of the relationship between financial hoarding and economic growth. Although existing research has consistently shown that financial hoarding has 
an impact on the economic growth, there is still no conclusion about whether financial hoarding promotes or inhibits the economy.

On the one hand, financial hoarding can promote economic growth. Specifically, for the households, the money in financial hoarding can bring benefits, and the wealth effect of households will increase personal welfare and stimulate consumption. For enterprises, overcapacity in the real economy will lead to dynamic inefficiency of the economy. Financial hoarding, by absorbing excess liquidity, will reduce over-investment in the real economy. So, it will increase marginal productivity efficiency of investment and eventually improve investment efficiency. For financial institutions, the monetary reserve inside the financial department can help them resist the risk from the financial market and secure the price stability of financial commodities. Thus, it will create a more stable environment to stimulate the economic growth. Since the 2008 financial crisis, the U.S. commercial banks tend to hold more emergency preparation, which improves their risk resistance ability due to the precautionary motive [19]. This part of financial hoarding effectively reduces the possibilities of a financial crisis, as the asset price always fluctuates violently before a crisis. For the country, with the background of globalization, the economic links among countries increase. The increase of reserves of a country's central bank will reduce the devaluation of its currency, so that it will stimulate exports, attract foreign investment, and promote its economic development. Central banks of East Asia countries deliberately increased their international reserves in order to cause devaluation of their countries' currency [20]. Thus, they can improve their national commodity competitiveness in the international market to promote exports. In the meantime, they also achieved the goal of economic recovery by attracting foreign capital to invest in the domestic market and increase infrastructure construction and employment opportunities. Lu [21] explained the relationship between climate threshold, financial hoarding, and economic growth. His study shows that climate threshold affects the cumulative effect of financial hoarding on economic growth. Chen and Zhang [18] made a new response to the statement of "financial hoarding" with the support of polarization theory. They found that the indirect path of "financial hoarding to industrial optimization to economic growth" had the most significant effect on China's economic development.

However, on the other hand, financial hoarding can inhibit the economic growth. Although financial assets can provide higher investment returns than the real economy, financial hoarding may reduce investment in the real economy. Its increase may deprive the investment in the real economy and hinder the economic growth by means of removing too much money from the real economy, which may consequently cause liquidity problems. Brossard and Saroyan [22] studied the price paid by banks for liquidity at the individual level and measured it by the overnight interest rate of unsecured loans on the e-MID trading platform. The study found that the hoarding behavior of banks significantly increased the price of financial assets in the market. Kang et al. [23] believe that hoarding leads to insufficient blood supply to the real economy. Small enterprises will significantly increase their preventive reserves or mutual short-term investments in order to prevent unexpected needs, while large enterprises pay more attention to transaction costs. Ren [24] analyzed the relationship between China's money supply and the development of small and medium-sized enterprises. He found that the loose monetary policy did not improve the financing difficulties of small and medium-sized enterprises. Through theoretical research and empirical analysis, he found that the financial hoarding was the important reason for this result. Ren et al. [25] found that monetary capital from other real industries flowed into various financial hoarding fields, which led to the phenomenon of capital "falling out of reality", "difficulty in financing for small and medium-sized enterprises", and "the mystery of Chinese currency". Berger et al. [26] explained that uncertainty about government economic policies harm the real economy through bank liquidity hoarding. Therefore, the increase of the scale of financial hoardings is not conducive to economic growth. Currency forms a new circulation system outside the currency circulation system of the real economy, which will have a negative impact on real investment, and the function 
of price as a means of allocating resources will inevitably be weakened. Generally speaking, financial hoarding is a new independent circulation flow system formed by the withdrawal of funds from the monetary circulation system of the real economy. The hoarding behavior will produce resistance to the development of the real economy and easily leads to systemic financial risks, which will make it more difficult for small and medium-sized enterprises to finance. The hoarding behavior significantly increases the price of financial assets, leading to the failure of the overall price allocation of resources.

At the same time, some research showed that the economic situation will also affect the financial hoarding scale. Aizenman et al. [27] found that the development of global economy will influence the hoarding international reserves (IR). Ashraf [28] showed that uncertainty about government economic policies motived banks to hoard more liquid assets for precaution.

To sum up, the above research only studied the effect of some funds in financial hoarding on economic output or added non-economic factors. However, researchers did not analyze the overall relationship between financial hoarding and economic growth directly. What is more, about whether financial hoarding promotes or inhibits economic growth, there is still no have a consistent conclusion. Hence, this research will directly study the relationship between financial hoarding and economic growth in China from both theoretical and empirical analysis. Moreover, this research will consider whether the relationship between financial hoarding and economic growth changes with the economic growth rate.

\section{Materials and Methods}

\subsection{Financial Hoarding and Economic Growth}

According to the theory of financial hoarding [2], which establishes the monetary cycle model of three sectors, including the enterprise (no financial enterprise), family, and financial institution. The enterprise and family constitute the real economy system, and the financial institution can be seen as the virtual economy system. The flow of fund in the currency cycle is directly related to the actual economic activity. In addition, the part of funds free from monetary cycle is called "financial hoarding". "Financial hoarding theory" focuses on the analysis of monetary cycle process between different economic sectors in a period of time. It emphasizes the concept of flow, different from the traditional macro analysis, which stresses the concept of stock at certain time points. However, the concept of stock is not in contradiction with the concept of flow. It just views the same thing from different aspects.

In the monetary cycle, the consumption plans made by the family sector lie in the disposable income. When the family consumption plan is satisfied, the rest of disposable income will be the family savings. The family can divide the money into cash in hand and deposit in the bank. They will need the cash to meet precautionary needs, and the deposit in the bank can bring interest income. If they have deposit in hand, they will get interest income with which they can purchase more goods and services in the next period. In the same way, after deducting wage expenses and remaining profits from income, the enterprise sector will get enterprise savings. They can also choose how much money is in cash and how much money is deposited in the bank. As a result, the family savings and enterprise savings will flow into the financial sector and become social savings. Meanwhile, some families and enterprises have extra money demand, so they will seek help from financial institutions. Thus, the financial institution will be the medium to provide financial services, which loads the money from the surplus sectors to the required sectors. The money surplus sectors gain the interest revenue while the money required sectors receive money, and, thus, all the social welfare is enhanced. In addition, some of the funds do not go into the above circle. One of them is used to deal with various financial assets to pursue profit from the financial assets price movement, and the other is used for emergency preparation to ensure the security of the financial system. Moreover, the funds in the financial hoarding also have interest earnings. In summary, from the above monetary 
cycle analysis, the savings are not all flowing into the cycle of money. Some funds are independent outside of the monetary cycle and become financial hoarding while flowing within the financial sector.

Binswanger not only defined "financial hoarding", but also introduced an equation to calculate the financial hoarding. Based on the monetary cycle model,

$$
Y_{t}+D_{t}+D F_{t}+\Delta M_{t}=G I_{t}+C_{t}+I F_{t}
$$

The left of the equation is the money supply, where $Y_{t}$ represents the income in the period of $t, D_{t}$ represents the depreciation allowances and retained earnings in the period of $t, D F_{t}$ represents the money deviating from the financial hoarding and back to the real economy in the period of $t$, and $\Delta M_{t}$ represents the net created money in the period of $t$. The right of the equation is the money demand, where $G I_{t}$ represents the total investment in the period of $t, C_{t}$ represents the consumption in the period of $t$, and $I F_{t}$ represents the money exiting the real economy and flowing into the financial hoarding.

With the savings equation $S_{t}=Y_{t}-C_{t}$, and the net investment equation $I_{t}=G I_{t}-D_{t}$, Equation (1) can be rewritten as follows:

$$
\Delta F_{t}=I F_{t}-D F_{t}=S_{t}-I_{t}+\Delta M_{t}
$$

where $S_{t}$ represents the savings in the period of $t, I_{t}$ represents the investment in the period of $t$, and $\Delta M_{t}$ donates the net increased amount of money supply in the period of $t$. Thus, calculates the net increased amount of financial hoarding $\Delta F_{t}$.

From the net increased amount of financial hoarding $\Delta F_{t}$ formula, the scale of financial hoarding is based on three parts. Firstly, if savings increase, the scale of financial hoarding will increase, and vice versa. When the family and enterprise sectors have earned more money, or when the little sacrifice of this period of consumption brings much more consumption in the next period, they will save the surplus money to the bank. This part of funds will be deposited or used to purchase financial products. Secondly, if investment increases, the scale of financial hoarding will decrease, and vice versa. If the enterprise wants to investment more, they will loan money from the bank. On the balance of the market conditions, if enterprises have good market prospects, they will investment more. When the total amount of money in the market cannot change immediately, it will lead to higher market interest rate. While the return of interest rate is high enough, the money in the financial hoarding will return to the real economy and become investment, due to the chasing profit property of money. Thirdly, if the net increased amount of money supply increases, the scale of financial hoarding will increase as well. When the money supply increases, the gap for the money demand is satisfied and there is still surplus money, which does not become investment and will enter into the financial virtual economy.

According to the above analysis, it can be concluded that the change of the scale of financial hoarding mainly depends on the return on investment of the real economy and the return on financial asset investment. When the return of financial asset investment is higher than the real investment project, the sector will tend to hold more financial assets, which means the financial hoarding scale increases, and vice versa.

Whether the total impact of financial hoarding on the economy is positive or negative depends on the specific economic environment and different periods. Although financial hoarding decreases the funds in the monetary cycle, which causes enterprise investment to crowd out, the actual situation is not so absolute. With investment in the real economy increasing, investment return declines, and the capital flows into financial hoarding, which will adjust the invalid investment in the economic system. In the meanwhile, financial hoarding funds also participate in various financial products to gain more profits. Finally, through the wealth effect, household consumption increases. This part of funds will return to the monetary cycle, which will not make the money in the monetary cycle decrease. That is, financial hoarding may not have a negative effect on non-financial sectors. In some ways, financial hoarding is conductive to economic growth. In addition, the part of funds 
may be used for emergency preparation to reduce the fluctuation in the financial market and provide a more stable environment for economic development. In order to understand whether the financial hoarding in China is promoting or inhibiting the economic growth, Hypothesis 1 is proposed in this study.

Hypothesis 1 (H1). Financial hoarding promotes economic growth.

With the development of finance and economy, financial institutions play a more and more important role in the economy. Through a series of innovations, they create so many new financial products that they can provide more convenient service for families and enterprises. At the same time, as the financial market develops, various financial products in the market will make the connection of financial market and economy tighter. The risk of the financial market will transfer to the economy and have impact on the real economy. Considering the economic growth speed has changed in recent years, the time-varying factor should be taking into account.

Based on Equation (1), financial hoarding scale is affected by two factors: the difference between savings and net investment $(S-I)$, and the amount of additional money $(\Delta M)$. When the economic prospect is prosperous, the expected return rate of real economic investment is high, and it is very likely to lead to $S-I<0$. On the other hand, when the economy prospect is depressed, the expected return rate of real economic investment is low, and it is likely to lead to $S-I>0$. However, the difference between savings and net investment is not completely affect financial hoarding scale. The change of the additional money $\Delta M$ will also affect financial hoarding scale. Change in the amount of additional money $\Delta M$ related to the regulation of interest rates by the central bank's monetary policies. Financial sector's risk attitude and willingness to lend will change with the economic environment. It can also be stated from another point of view that the changes in the economic environment will lead to changes in the expected investment return. When the expected return on real economic investment rises, due to the decision of increasing the real economy investment, the investment funds will flow into the real economy and cause the scale of financial hoarding to decrease. However, the decrease of financial hoarding scale is only temporary. The market money demand will eventually influence the central bank's regulation policy. Therefore, in different stages of economic development, changes of the amount of financial hoarding $\Delta F$ is uncertain.

Whether the total impact of financial hoarding on the economy is positive or negative depends on the specific economic environment and different periods. Hypothesis 2 is proposed in this study.

Hypothesis 2 (H2). The relationship between financial hoarding and economic growth has regime change.

\subsection{Empirical Framework \\ 3.2.1. Model}

At present, although there are empirical studies on the relationship between financial hoarding and economic growth, empirical analyses have not directly discussed the relationship between financial hoarding and economic growth in these studies. Among them, some literature did not propose the definition of financial hoarding and measure the scale of financial hoarding. Instead, they measured part of the financial hoarding and regarded it as the variables of the virtual economy sector, considering the influence of the virtual economy sector on the growth of the real economy. Some literature added other non-economic sector factors when considering the relationship between financial hoarding and economic growth, without directly discussing the relationship between financial hoarding and economic growth. Through theoretical analysis, it is evident that financial hoarding and economic growth will interact, but whether financial hoarding will promote or inhibit China's economic growth is currently unknown. 
To test Hypothesis 1, a simultaneous equations model was built for quantitative analysis of the relationship between financial hoarding and economic growth. The simultaneous equation model can simultaneously examine the interaction between financial hoarding and economic growth. The influence of economic growth on financial hoarding and the influence of financial hoarding on economic growth can be directly investigated through the third and fourth equation in the simultaneous Equations (3), respectively.

$$
\left\{\begin{array}{c}
C=\alpha_{0}+b Y d \\
I=\beta_{0}+c S \\
F=\gamma_{1} Y+\gamma_{2} r \\
Y=\lambda_{1} F+\lambda_{2} K
\end{array}\right.
$$

The simultaneous equations model includes four equations. Equation one is the consumption equation, in which $C$ represents the per capita consumption of residents, $b$ represents the marginal consumption tendency, $Y d$ represents the per capita disposable income, and $\alpha_{0}$ is a constant term. Equation two is an investment equation, in which $I$ represents investment, $c$ represents the ratio of investment and savings, $S$ represents the savings, and $\beta_{0}$ is a constant term. Equation three is financial hoarding equation, in which $F$ represents the net increasing amount of financial hording, $Y$ represents the economic output, $r$ represents the market interest rate. Equation four is the economic output equation, in which $K$ represents the capital stock.

Through theoretical analysis, in different periods of economic growth, the impact of financial hoarding on economic growth may change. Since the simultaneous equations model is unable to analyze dynamic changes between financial hoarding and economic growth in different economic conditions, in order to test Hypothesis 2, Markov Switching Vector Autoregressions (MS-VAR) model is used to study the dynamic relationship between financial hoarding and economic growth. The MS-VAR model controls the regime transfer mechanism by introducing the state variable $S_{t}$. The different values of $S_{t}$ represent different states of the economy. The regression parameters in the model change with the different $S_{t}$, and the state transformation follow the Markov random process. The advantage of this model is that the state information is not required in the model, which can automatically capture the state information through the data. With changes in world economic environment and implementation of national economic reforms, the relationship between financial hoarding and economic growth may change. In order to study the nonlinear dynamic interaction between financial hoarding and economic growth, this paper constructs two regimes MS-VAR model of three variables, which is economic growth rate $d \ln Y \_S A$, the increasing rate of financial hoarding $d \ln F \_S A$, and interest rate $r$.

Model 1 can directly investigate the impact of financial hoarding on economic growth, and it can make up for the blank in the existing literature, which does not directly discuss the influence between financial hoarding and economic growth. Model 2 takes into account whether the impact of financial hoarding on economic growth has changed under the change of economic growth rate, which is in line with the actual background of changes of economic growth rate in China, and it further discusses the relationship between financial hoarding and economic growth under different economic growth rates. Therefore, the two models in this paper can be used to analyze the relationship between financial hoard and China's economic growth in detail, which is consistent with the actual situation of China's economy.

\subsubsection{Data}

This paper utilizes China's time series data of the first quarter of 2003 through the fourth quarter of 2016, about 56 quarterly samples in total. The data are derived from CEInet Statistics Database. There are some points that need to be explained. Firstly, since this paper uses quarterly data, the annual data of urban and rural population are converted to quarterly data using Eviews8.0 software. Secondly, in order to exclude the interference of quarterly influence, this paper uses Census X12 method to adjust variables with seasons. 
After the treatment, the per capita disposable income $Y d$, per capita consumption $C$, gross domestics savings $S$, investment $I$, additional money supply $\Delta M$, financial hoarding $F$, economic output $Y$ and capital stock $K$ are represented by $Y d \_S A, C \_S A, I \_S A, \Delta M \_S A$, $F \_S A, Y \_S A, K_{S A}$, respectively. Finally, in order to obtain smooth sequences, this paper takes the logarithmic difference of the economic output $Y_{-} S A$ and financial hoarding $F \_S A$, and then gets the economic growth rate $d \ln Y \_S A$ and financial hoarding growth rate $d \ln F \_S A$.

The variables are as follows:

(1) The financial hoarding: $F$.

Following Binswanger [2], this paper used the equation of the net increased amount of financial hoarding, also called the scale of financial hoarding, and we write $F$ for short.

The changes in the financial hoarding scale from the first quarter of 2003 to the fourth quarter of 2016 in China are shown in Figure 1. The calculation results are consistent with the study of Zhu's [14] annual estimations.

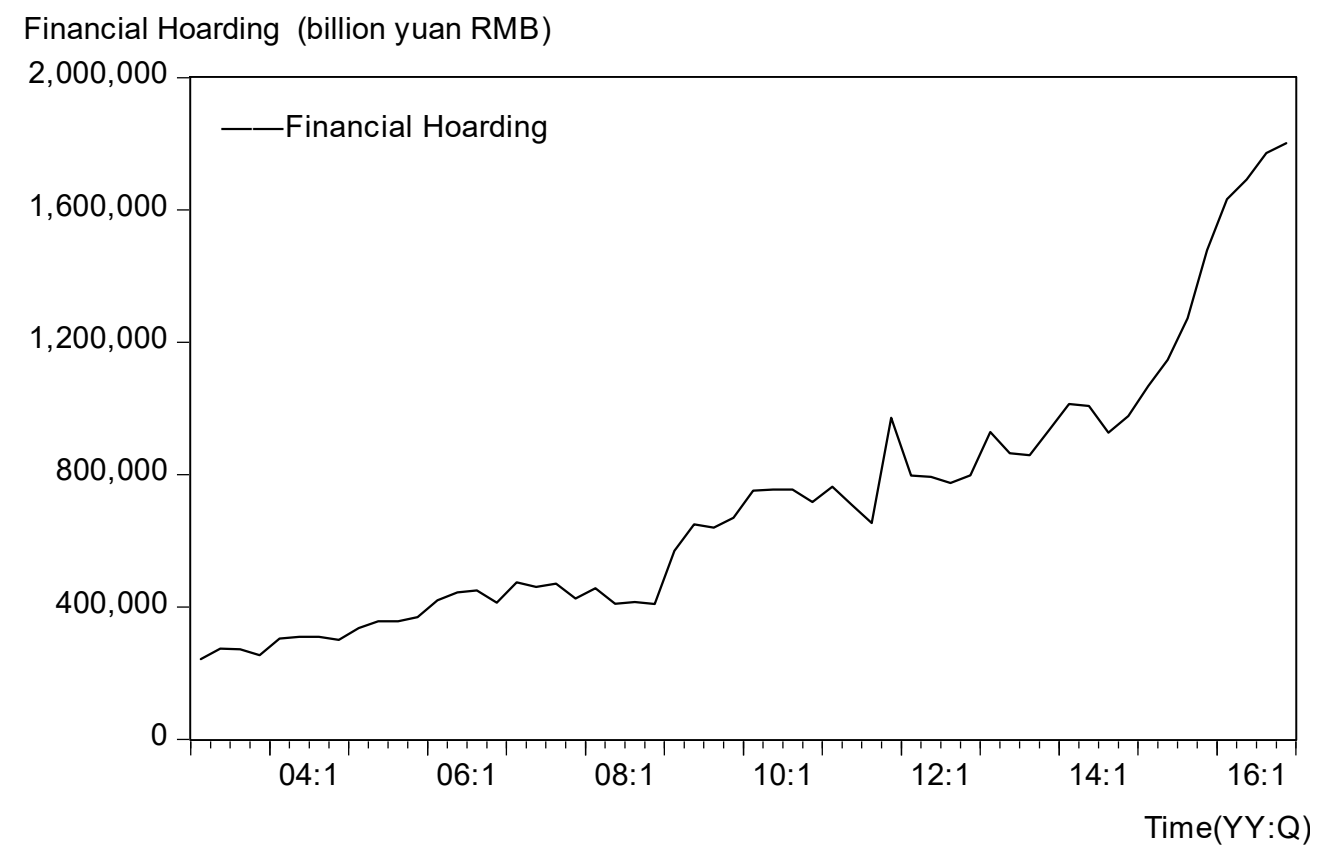

Figure 1. The change of China's financial hoarding scale from the first quarter of 2003 to the fourth quarter of 2016.

Since the first quarter of 2003, the financial hoarding scale is 242,178 billion yuan and showing an upward trend and in the fourth quarter of 2016 jumped to 1801706 billion yuan. It increases by nearly 7.4 times in the past 14 years, which shows that China has more money free from the real economy. During the period, China's economic growth made remarkable achievements and accumulated a lot of wealth. Part of the wealth went into the financial hoarding and prevented the scale of financial hoarding from expanding quickly. In terms of growth rate, it accelerated after 2014, after which year the scale of financial hoarding increased rapidly. With China's economy entering a "new normal" state, it has shifted from high speed to medium and high-speed development. The central bank has made loose monetary policies to stimulate the economic development. At the same time, in order to prevent and control systemic risks, various financial institutions have made full preparation to avoid risks. The above factors reduce the rapid expansion of the scale of financial hoarding. The amount of financial hoarding becomes huge and shows an accelerating growth trend. This will undoubtedly have an important impact on economic growth.

(2) The per capita disposable income: $Y d$. 
For the data before 2013, the database only offers the quarterly data of cumulative per capita cash income of rural families and urban residents. By taking the difference of cumulative per capita cash income of rural families and cumulative per capita cash income of urban residents, we got the added value of each quarter. Using the rural population and the urban population as weight and matching the corresponding disposable income, we got the per capita disposable income $(Y d)$. Because the National Bureau of Statistics announced the quarterly data of cumulative per capita disposable income since September 2013, we just took the difference of the quarterly data of cumulative disposable income of residents since 2014, and then calculated the added value of each quarter $(Y d)$.

(3) The per capita consumption: $C$.

Similarly, for the data before 2013, the database only offers the quarterly data of cumulative per capita cash consumption of rural households and the per capita consumption of total household expenditure of urban residents. By taking the difference, we got the added value of each quarter, and then by matching with the rural population and the urban population, we got per capita consumption (C). The National Bureau of Statistics announced the cumulative consumption expenditure per capita since June 2013. Therefore, the cumulative consumption expenditure of residents can be achieved after 2014, and by taking the difference, the added value of each quarter will be obtained.

(4) The gross domestic savings: $S$.

In this paper, the per capita savings is measured by $Y d-C$, which is multiplied by the total number of people in the estimated period to get the gross domestic savings.

(5) The investment: $I$.

Taking the difference of the cumulative investment completion of fixed assets (excluding farmers), we got the added value of each quarter as the investment $I$.

(6) The additional money supply: $\Delta M$.

Utilized the reserve currency to represent the base currency $B$. The money multiplier $m$ is measured by $m=M_{2} / B$. Then we calculated the amount of newly increased money $\Delta M=M_{1} \times m-M_{1}$.

(7) The economic output: $Y$.

The gross domestic product (GDP) is used to measure the level of economic output. Utilized the quarterly GDP as the economic output $Y$.

(8) The capital stock: $K$.

As China has no official statistical data of capital stock, this paper utilized the estimation of Ma [17], which calculated China's 2003-2016 capital output ratio based on 1978 constant price. The capital stock $K$ was measured by the product of the ration and quarterly GDP.

(9) The market interest rate: $r$.

We utilized the weighted average interest rate of interbank lending to represent the market interest rate level $r$. In order for all variables to be in the same dimension, the level of interest rate is magnified by 10,000 times.

\section{Results}

\subsection{The Long-Term Relationship between Financial Hoarding and Economic Growth}

Before estimating the simultaneous equation model, the identification of the simultaneous equation model must be taken into account. Through the identification process, the four equations in the simultaneous equation model all can be identified.

We estimated the parameters of the model with the two stage least square (TSLS) method using the Eviews8.0 software. The regression results of the important parameters are shown in Table 1. 
Table 1. Parameter estimation results.

\begin{tabular}{ccccc}
\hline Variables & Coefficient & Std. Error & t-Statistic & Prob. \\
\hline$b$ & 0.7052 & 0.0099 & 71.0866 & 0.0000 \\
$c$ & 6.7683 & 0.3388 & 19.9803 & 0.0000 \\
$\gamma_{1}$ & 8.1561 & 0.3695 & 22.0720 & 0.0000 \\
$\gamma_{2}$ & -5.3789 & 1.6211 & -3.3180 & 0.0011 \\
$\lambda_{1}$ & 0.0212 & 0.0116 & 1.8227 & 0.0697 \\
$\lambda_{2}$ & 0.1135 & 0.0112 & 10.1019 & 0.0000 \\
\hline
\end{tabular}

The adjusted $R^{2}$ of each equation is $0.9892,0.8786,0.8751$, and 0.9356 , respectively, and the coefficients all pass the test of significance.

It can be seen from the first equation $\left(C=\alpha_{0}+b Y_{d}\right)$ that the marginal consumption tendency $b$ is 0.7052 . This result means that residents will spend $70.52 \%$ of their disposable income on consumption, and the remaining $29.48 \%$ disposable income is used for savings. In fact, this phenomenon indicates that there exists a high savings rate. The high savings rate means family income has not been completely transformed into effective demand of the family. With the development of China's financial market, savings can gain higher earnings than bank deposits by investing in financial products. Residents' increasing savings is an important source of financial hoarding. With the increase of savings, the financial hoarding scale will increase as well.

It can be seen from the second equation $\left(I=\beta_{0}+c S\right)$ that the ratio of investment and savings $c$ is 6.7683. The result shows that every increase of 1 yuan in family savings will bring 6.7683 yuan enterprise investment through bank credit expansion. By transforming Equation (1), $I=S+\Delta M-\Delta F$. The net investment is influenced by three factors: the current savings, the newly added money supply, and financial hoarding. The fact that the ratio of investment and savings is more than 1 indicates that the money source of investment not only comes from savings, but also is influenced by the added money supply and financial hoarding, and the coefficient is significantly more than 1 , which means cannot ignore the other two factors when considering the money source of the investment.

From the third equation $\left(F=\gamma_{1} Y+\gamma_{2} r\right)$, the coefficient influence of economic output on financial hoarding is $\gamma_{1}=8.1561$, which indicates that when the economic output increases $1 \%$, the scale of financial hoarding increases $8.1561 \%$. The coefficient is positive, which shows that the economic output has a positive effect on financial hoarding. The reason may be that the increase of economic output will raise residents' disposable income, while the level of consumption does not increase dramatically, so the increased revenue will be transformed into savings. The financial hoarding scale will increase when they purchase financial assets. Meanwhile, the increase of economic output leads to the increase of market money demand. The central bank will increase currency supply. When the real demand for money is less than the central bank's new currency supply, this part of the surplus funds will be hoarded up for financial hoarding. The interest rate coefficient $\gamma_{2}$ is negative, indicating that the interest rate has a negative impact on financial hoarding. When the real economy increases the money demand, the real market investment will provide higher compensation for the use of money, and the level of interest rate increases. When the return on investment is high enough, the money will flow out from financial hoarding to seek high profit properties. Thus, the scale of financial hoarding will decrease.

From the fourth equation $\left(Y=\lambda_{1} F+\lambda_{2} K\right)$, the coefficient influence of financial hoarding on economic output is $\lambda_{1}=0.0212$, which shows that the scale of financial hoarding increases $1 \%$, and the economic output increases $0.0212 \%$. The coefficient is positive, which indicates that financial hoarding has a positive effect on economic growth. Economic growth will bring dividends to financial hoarding. The reasons may be attributed to the following. Firstly, it can stimulate household consumption. As financial assets become a symbol of family wealth, the level of family wealth increases with the appreciation of financial assets. The wealth effect due to the increased scale of financial hoarding stimulates consumption and promotes economic growth. Secondly, it will encourage enterprises to 
improve production efficiency. The financial sector is not a production sector, and it cannot create value. The financial sector guides the flow of funds into the most efficient enterprises by affecting the resource allocation. The allocation of resources makes enterprises improve production efficiency, and, thus, the economic output increases. Thirdly, it maintains the stability of the economic and financial system. Part of the financial hoarding is the financial sector's risk preparation. Though the fund is free from the real economy, it can reduce the possibility of a financial crisis. Therefore, it can maintain the stability in the financial market and consolidate market confidence so as to provide a good environment for economic development. The coefficient of capital stock on economic output $\lambda_{2}$ is 0.1135 , which indicates that the capital stock increases by $1 \%$ and the economic output will increase by $0.1135 \%$. As one of the factors of production, the increase of capital stock will promote the increase of economic output. Compared with $\lambda_{1}$, it reveals that the capital stock has a greater influence on economic growth than financial hoarding. The economic growth is mainly due to the capital stock, rather than financial hoarding. The capital stock is still the primary driving force for economic growth.

Comparing the third and fourth equation, the results show that economic growth has greater positive impact on financial hoarding than financial hoarding on the economic growth. When the economic growth, the scale of financial hoarding will increase. The empirical results fit the actual situation. China's economy grows rapidly in the sample interval. At the same time, the scale of financial hoarding boosts up. While the empirical results revealed that financial hoarding promotes economic growth. Compared with capital stock, the degree of financial hoarding that promotes economic growth is limited. The result meets the expectation. Finance is the factor that accelerates economic growth, not the major factor to decide the economic growth.

In summary, from the simultaneous equation model, there is a positive correlation between financial hoarding and economic growth. In the long term, financial hoarding promotes economic growth, which, in turn, contributes positively to financial hoarding. Thus, the above empirical analysis confirms Hypothesis 1: financial hoarding promotes economic growth.

\subsection{The Relationship between Financial Hoarding and Economic Growth in Different Economic Growth Regimes}

Does the relationship between financial hoarding and economic growth change with the economic growth rate in China? To find out, this paper uses the MS-VAR model to test Hypothesis 2.

\subsubsection{Model Setting}

The first step of the MS-VAR model analysis is to test the stability of the variables and select the appropriate model form.

When using the application of time series model, the stability of variables should be taken into account. In order to prevent spurious regression, the augmented Dickey-Fuller (ADF) unit root test is used to identify the stability of the variables. The null hypothesis is that the variable has a unit root, and the alternative hypothesis is that the variable is a stationary time series. Table 2 shows the test results.

Table 2. Variables stationary test.

\begin{tabular}{ccccc}
\hline Variable & $\mathbf{( C , T , K )}$ & t-Statistics & $\mathbf{5 \% ~ L e v e r ~}$ & Prob \\
\hline$d \ln Y \_S A$ & $(\mathrm{C}, 0,0)$ & -3.0385 & -2.9166 & 0.0376 \\
$d \ln F \_S A$ & $(\mathrm{C}, 0,0)$ & -9.3039 & -2.9166 & 0.0000 \\
$r$ & $(\mathrm{C}, 0,0)$ & -4.4622 & -2.916 & 0.0007 \\
\hline
\end{tabular}

Note: $(\mathrm{C}, \mathrm{T}, \mathrm{K})$ represent intercept term, time trend term, and model lag order, respectively, and the lag order of the model is determined by SIC criterion. 
From the results, the ADF statistic of each sequence is less than $5 \%$ critical value, and the $p$ value is less than 0.05 , indicating that all variables are stable at $5 \%$ significance level. Based on the result that all variables are stationary, further select the appropriate model form.

The model is estimated by using the OX-MSVAR package on the Givewin2 platform. According to the overall trend of China's economic growth rate from 2003 to 2016, divided this period into two regimes. This paper uses two regime MS-VAR model depending on the economic state, which is divided into medium speed economic growth regime and high-speed economic growth regime.

The MS-VAR model is very sensitive to the choice of lag order, so it is necessary to choose a suitable one. Usually, the quarterly data of 4 is selected as the maximum lag. The optimal lag number is selected according to the optimal delay test, and the results are shown in Table 3. This paper uses four indicators, AIC, HQ, SC, and LogL, to select the optimal lag. It can be seen that the better order is 1 . When the lag stage of the model is 1 , the value of AIC, HQ, and SC are all small, so we chose lag stage 1 for modeling.

Table 3. MS-VAR model optimal delay test.

\begin{tabular}{ccccc}
\hline Lag & AIC & HQ & SC & LogL \\
\hline MSI(2)-VAR(1) & 12.5081 & 12.8348 & 13.3553 & -314.7195 \\
MSI(2)-VAR(2) & 12.5806 & 13.0381 & 13.7702 & -301.3862 \\
MSI(2)-VAR(3) & 12.9703 & 13.5601 & 14.5088 & -296.2274 \\
\hline
\end{tabular}

There are two main categories of MS-VAR models. One is MS-VAR model based on intercept adjustment, that is, MSI-VAR model, and the other is MS-VAR model based on mean value adjustment, namely MSM-VAR model. This paper uses four indicators, AIC, HQ, SC, and LogL, to select an appropriate model. The results are shown in Table 4 . It can be seen that the MSMH(2)-VAR(1) model is the best suitable for this research. When the selected model is MSMH(2)-VAR(1) model, the value of AIC, HQ, and SC are all small. So, the MSMH (2)-VAR (1) model is selected for empirical study.

Table 4. MS-VAR model type selection.

\begin{tabular}{ccccc}
\hline Model Type & AIC & HQ & SC & LogL \\
\hline MSI(2)-VAR(1) & 12.5081 & 12.8348 & 13.3553 & -314.7195 \\
MSIH(2)-VAR(1) & 11.9329 & 12.3449 & 13.0011 & -293.1892 \\
MSIA(2)-VAR(1) & 12.1925 & 12.6470 & 13.3711 & -297.1970 \\
MSIAH(2)-VAR(1) & 11.6757 & 12.2155 & 13.0753 & -277.2436 \\
MSM(2)-VAR(1) & 12.4823 & 12.8090 & 13.3294 & -314.0211 \\
MSMH(2)-VAR(1) & 11.8808 & 12.2927 & 12.9490 & -291.7815 \\
MSMA(2)-VAR(1) & 14.8975 & 15.3521 & 16.0762 & -370.2333 \\
MSMAH(2)-VAR(1) & 15.1195 & 15.6595 & 16.5194 & -370.2333 \\
\hline
\end{tabular}

After selecting the type of MS-VAR model, the linear test is conducted. The linear test (DAVIES test) results show that the nonlinear MS-VAR model is superior to the linear VAR model.

\subsubsection{Regime Probabilities Analysis}

The MSMH (2)-VAR (1) model can depict the characteristics of China's economic fluctuations. This model divides China's economy into two regimes. Regime 1 represents the economy with a medium speed growth rate, and regime 2 represents the economy with a high economic growth rate. The probabilities diagrams of the regimes are shown in Figure 2. Since 2003, China's economy has maintained a rapid growth rate. From the first quarter of 2003 to the third quarter of 2006, the economy was in the medium speed growth area. At the eve of the US subprime mortgage crisis, which occurred in 2008 and 
greatly affected China's economy, it even reached a rapid growth rate regime. With the spread of the American financial crisis, China's exports, investment, and consumption decreased, and the economic growth rate gradually declined in the following quarters and returned to the medium speed growth regime. To get out of the financial crisis aftermath, China's government started the "four trillion" stimulus program policy, trying to expand domestic demands and stimulate economic growth. Due to the effort from all walks of life, the economic growth picked up briefly. In 2011, the economic growth rate soared up and returned to the rapid growth regime. However, affected by the adverse influence of the external environment, such as the escalation of the European sovereign debt crisis, the world's overall economic environment was sluggish and economic growth rate declined slightly. During this period, the Chinese government launched the policy of "supply side structural reform" and "public and entrepreneurship innovation". With the marginal revenue of elements diminishing and the labor dividend gradually disappearing, the economic development entered into the "new normal" state, and the economic growth turned into the medium speed growth regime again. Based on the above analysis, it is roughly consistent with the reality of China's economic situation.
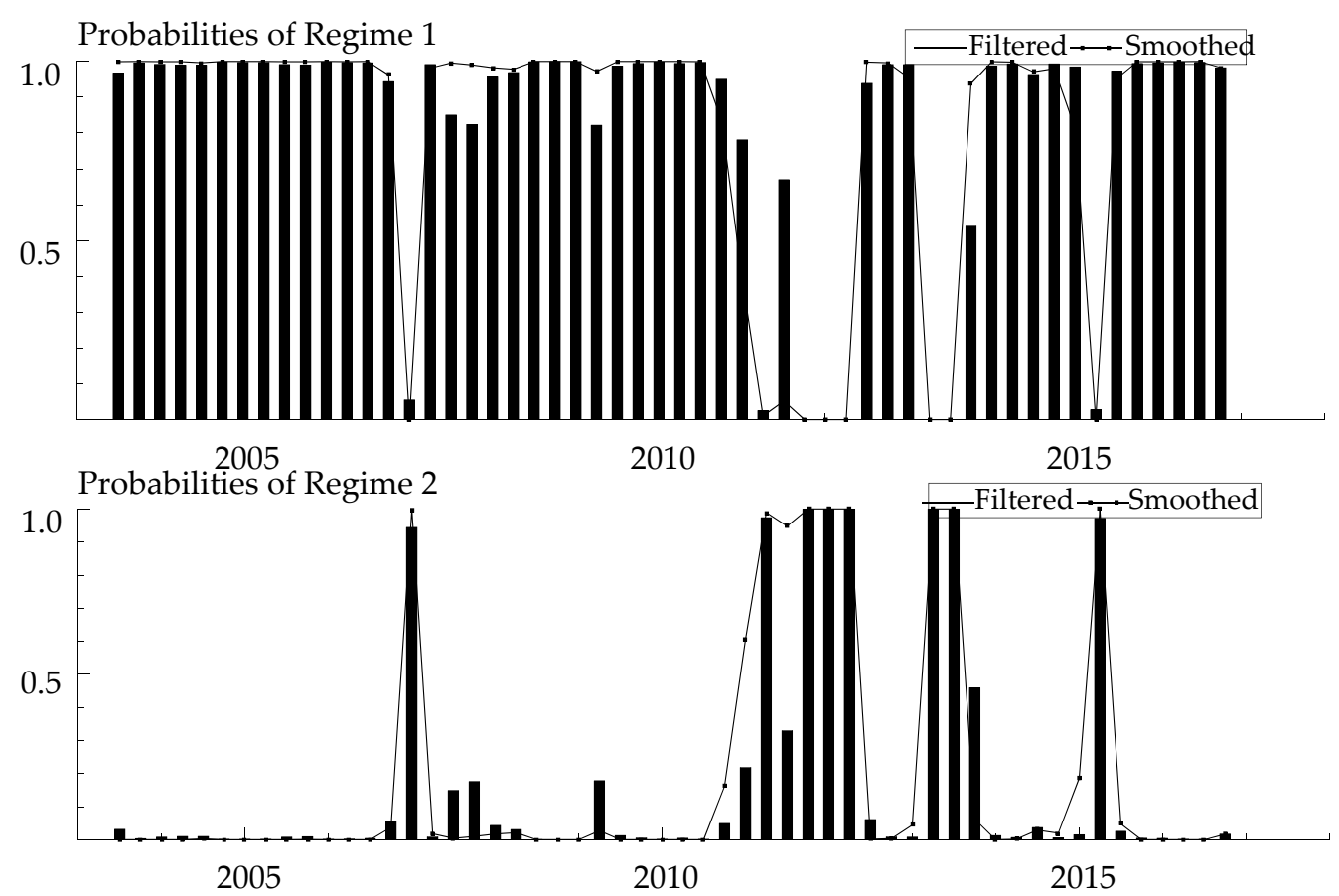

Figure 2. Probabilities of Regimes.

\subsubsection{Impulse Response Analysis}

To illustrate the dynamic relationship between financial hoarding and economic growth, what will be the response of one variable when the other variable has an accident impact? This paper utilizes the impulse response function to analyze the interaction between financial hoarding and economic growth.

The dynamic effect of economic output on the impact of financial hoarding is shown in Figure 3. In this figure, the horizontal coordinate represents the time interval after the pulse occurred, and the vertical coordinate represents the response of financial hoarding growth rate when the economic output growth rate is affected by a positive pulse. 

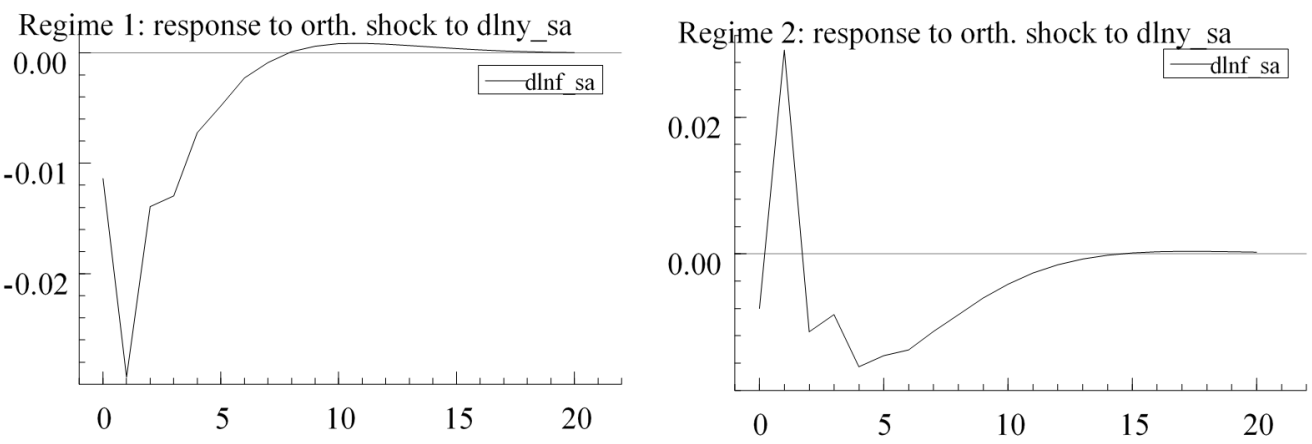

Figure 3. Impulse response to shock to economy in different regimes.

Give the economic growth rate one-unit positive impulse, namely, the economic growth rate rises. In both regimes, the financial hoarding growth rate presents negative changes in the current quarter. When the economic growth changes, the central bank does not change the amount of money supply due to the expectation stickiness. When the demand for money increases, in order to ensure the smooth progress of the transaction, part of the funds will flow from financial hoarding into the real economy, causing the financial hoarding growth rate to be negative. After one quarter, the impact of economic growth on financial hoarding is exactly opposite under different regimes. In the medium speed regime, economic growth will inhibit financial hoarding scale growth, while in the high-speed regime, economic growth promotes financial hoarding scale growth.

In regime 1, namely the economy with a medium growth rate, the financial hoarding growth rate is always a negative value. In the first quarter, it reaches the maximum negative effect -0.029 . After that, it gradually converges to 0 . There is almost no influence after 16 quarters. It may be that after the first quarter, families, businesses, and governments adjust their economic expectations and increase expected economic growth rate. When family disposable income increases, the households will increase their consumption, especially long-term consumption such as housing, or other consumption in order to improve the quality of life. As a result, the increase of family consumption is larger than that of income, and the savings decreases. As the economic growth rate increases, enterprises will be more confident in the future market. They will increase investment in R\&D, equipment renewal, and other production activity to increase productivity. After the first quarter, the central bank will increase the money supply. However, at the same time, the government should prevent the economy from being overheated. The central bank will moderately reduce the amount of money supply to create a favorable economic environment.

In regime 2, namely the economy with a high growth rate, the financial hoarding growth rate has a negative impact in the current quarter. However, in the second quarter, it suddenly rises sharply and reaches the maximum positive impact 0.028 . Later, the response keeps declining, and becomes negative. In the fourth quarter, it reaches the maximum negative effect -0.016 . Later, the response gradually converges to 0 . There is almost no effect after the sixteenth quarter. This pattern shows that in the period of high-speed economy growth, people are overoptimistic about the future economy, and they expect that the future economic growth rate will increase considerably. Families and enterprises will increase consumption and investment, causing the financial hoarding scale to decrease. The central bank supplies so much money that it is far more than the real demand eventually making the financial hoarding scale to increase. When money is poured into the financial hoarding, it will drive up the price of financial assets, so the return from financial hoarding will increase and attract more money to flow into it. However, the increase of investment in financial hoarding cannot continue. Thus, the growth rate of financial hoarding is still positive, but the speed slows down. For a while, the central bank will adjust the money supply to withdraw the surplus money supply, and then the growth rate of financial hoarding becomes negative. 
With the passage of time, family, business, and the central bank continuously revise their expectations, adjust consumption, investment, and money supply plan. They will achieve a balance between supply and demand of funds ultimately.

The dynamic effect of financial hoarding impact on economic output is shown in Figure 4. In this figure, the horizontal coordinate represents the time interval after the pulse occurs, and the vertical coordinate represents the response of economic output growth rate when the financial hoarding growth rate is affected by a positive pulse.
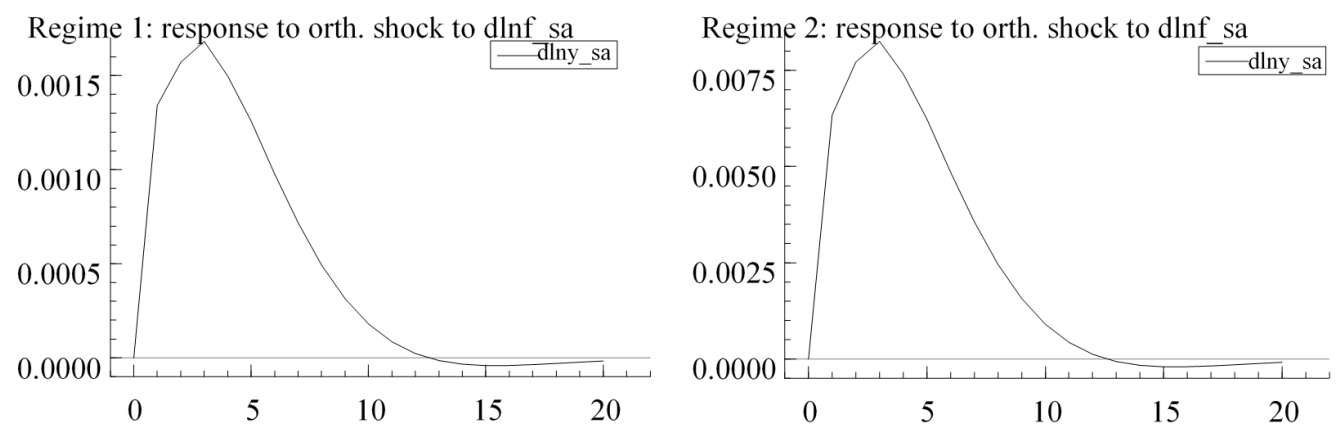

Figure 4. Impulse response to shock to financial hoarding in different regimes.

Give the financial hoarding growth rate one-unit positive impulse, namely the financial hoarding growth rate rises. It can be found that the growth rate of economic output in the two regimes is roughly the same, but the range is different. It reaches the maximum positive effect in the third quarter, and it continues being positive afterwards. Then, it slips slowly, and after the sixteenth quarter, the response gradually disappears. Under regime 1 , the maximum positive effect is 0.0016 , while the maximum positive effect is 0.008 under regime 2. The response pattern shows that whether the economy is in medium or high growth period, financial hoarding will promote economic growth. By comparison, in the regime of rapid economic growth rate, financial hoarding has greater positive influence on economic growth.

The possible reasons may be as follows. First of all, the increase of the growth rate of financial hoarding enhances the wealth level of households, so that they increase consumption, which in turn, will stimulate the economy to a large extent. Secondly, under the condition that the supply of financial assets is limited and cannot increase immediately, the marginal return of financial hoarding decreases with its increase. In order to seek for greater profit, funds will flow from the virtual economic sector to the real economic sector. When the real economy has received funds, the investment increases and the economic output increases. Finally, the increase of financial hoarding caused by increased risk preparation enhances the ability to resist the market credit risk, which will increase enterprises' investment passion and economic output.

Compared with the medium regime, in the high-speed regime, the wealth effect of financial hoarding is greater, and the household consumption increases more. Meanwhile, the real economy sector has more capital demand, and the expected return rate of investment is high. The cost of capital will influence the allocation of funds, which contributes to a greater level of production efficiency and increases the economic output to a greater extent. It can stimulate economic growth more substantially.

With the automatic adjustment of the funds, investment returns of the virtual financial sector and the real sector will tend to be consistent. The promotion effect of financial hoarding growth rate on economic output growth rate gets weak gradually.

In summary, economic output has different effects on financial hoarding in different economic states. In the period of medium economic growth, the economic growth will inhibit the increase of financial hoarding scale. However, in the period of rapid economic growth, the economic growth will increase the scale of financial hoarding at the beginning and then inhibit it. In any regime, financial hoarding growth will promote economic growth. In the period of rapid economic growth regime, the influence is greater. Moreover, it can 
be found that economic output has greater influence on financial hoarding than financial hoarding on economic output. The conclusion is consistent with the simultaneous equation findings. Thus, the above empirical analysis confirms Hypothesis 2: The relationship between financial hoarding and economic growth has regime change.

\section{Discussion}

According to the conclusions of this paper, this research makes the following suggestions.

First, a favorable environment should be established for real economic development. If the interest rate return of real economy higher than virtual economy, funds will flow from the virtual economy to the real economy. The government can create a friendly environment for economic growth through implementing the positive fiscal and monetary policies, enhance infrastructure construction, hold trade conferences, exhibitions and fairs, etc., so that the confidence of the enterprises' investment in the real economy would be enhanced. The consumers will increase consumption. The factories will produce more products and invest more facilities. At the same time, the potential domestic market will attract foreign investment. Better business environment will promote economic development.

Second, the capital market should be further developed. In recent years, the scale of financial hoarding has increased considerably, which will cause the problem of financial risks. The aggregate size of the Chinese economy increases rapidly, there is no doubt that the scale of financial hoarding will inevitably increase. More and more funds circulate in the virtual economy and are invested in the financial products, and the financial risks shoot up. History tells us management of the financial risks are important. Thus, financial innovation and financial reform can improve the financial market efficiency, prevent financial risks, and achieve an effective allocation of funds.

Third, the government needs to provide more policies to support new and high technology industries. New and high technology industries have potential for development. The investment in new and high technology industries can give the investors the highest interest rate return. The government could make some policies, such as tax preference, to guide the funds flow into new and high technology industries, which will help to promote technological progress, industrial upgrading, and achieves high-quality economic development.

\section{Conclusions}

Contrary to previously existing analyses, this article studied the relationship between financial hoarding and economic growth directly. In more detail, this article took the real situation into accord, explored the relationship between financial hoarding and economic growth change with growth rate changed. This article not only carries out the theoretical analysis but also empirical analysis. As mentioned above, the research on financial hoarding has indispensable theoretical and practical significance.

From the theoretical analysis, this paper found that when the rate of return of the virtual economic system is higher than that of the real economy system, a large amount of capital will stay in the virtual economic system and form a financial hoard. At the beginning of its emergence, the virtual economic system was created to serve the real economy and it grew with the development of the real economy. Therefore, financial hoarding is the inevitable product of the development of the real economy to a certain stage. Financial hoarding can enrich the investment channels of investors, absorb excess money in the market, avoid inflation caused by oversupply of currency, and promote the continuous prosperity of virtual economy. However, a large number of financial hoardings should be avoided, which will bring challenges to the development of national economy, such as distorting asset prices, aggravating financial risks, and affecting the transmission effect of economic policies. The theoretical analysis reveals that in different economic states, the relationship between financial hoarding and economic growth will change.

For the empirical analysis, this paper used quarterly data of the first quarter of 2003 through the fourth quarter of 2016, and this paper discussed the status of China's financial hoarding and studied the relationship between financial hoarding and economic growth 
in China. The main conclusions are as follows: (1) After calculations, China's financial hoarding scale kept increasing, and the speed accelerated after 2014. The large amount of financial hoarding inevitably will affect economic growth, so that it is of great significance to study the relationship between financial hoarding and economic growth. (2) In order to explore the relationship between financial hoarding and economic growth in the long term, we built the simultaneous equations model, which includes four equations. The results of simultaneous equations model show that financial hoarding and economic growth promotes each other in the long term. Through comparison, it is found that economic output has greater influence on financial hoarding than financial hoarding on economic output. (3) We used the MS-VAR model to empirical analyze whether the relationship between financial hoarding and economic growth will change when the economic growth rate change. The results of nonlinear MS-VAR model show that the responses of financial hoarding to economic growth are different when the economic growth rate changes. In the medium growth rate regime, economic growth will inhibit the scale of financial hoarding, while in the rapid growth rate regime, the economic growth will increase the scale of financial hoarding. However, in any regime, financial hoarding growth will promote economic growth, but the degree of influence is different. In the rapid economic growth regime, financial hoarding has greater influence on economic growth.

According to the conclusions of this paper, we make the following suggestions. First, a favorable environment should be created for real economic development. The confidence of the enterprises' investment in the real economy would be enhanced by the implementation of positive fiscal and monetary policies. Funds will flow from the virtual economy to the real economy, and better promote economic development. Second, the capital market should be further developed. In recent years, the scale of financial hoarding has increased considerably, which will lead to financial risks. Financial innovation and financial reform can improve the financial market, prevent financial risks, and achieve an effective allocation of funds. Third, the government needs to provide more policy support for new and high technology industries. The rate of return on investment should be increased for new technology industries. By doing so, it guides capital flows into high-tech industries, promotes technological progress and industrial upgrading, and achieves high-quality economic development.

There are some limitations to this research. The research showed that with the economic growth, the scale of financial hoarding will inevitably increase. There is no doubt that the financial hoarding will bring up the problem of financial risk. Due to the limitations of data indicators, this paper did not construct a comprehensive index of financial risk. What is more, this research is most concerned about the relationship between financial hoarding and economic growth. This research did not explore the relationship between financial hoarding, financial risks, and economic growth.

Therefore, the findings of this research also put forward potential topics for future research. Further study can try to build a comprehensive index of financial risk to observe systemic financial risk. Money supply will increase with the development of national economy, and the emergence of financial hoard is inevitable. The key is to pay attention to the scale of financial hoarding and the increase of systemic financial risk. We suggest to comprehensively consider all kinds of investment tools in the field of financial hoard, such as basic financial tools, derivative financial tools, real estate markets, rare and precious metal products and to combine the risk of each investment tool to build a comprehensive risk index, which can effectively monitor the risk changes caused by the financial hoarding. Moreover, we suggest to explore the relationship between financial hoarding, financial risks, and economic growth and whether the relationship will change or not when the economic growth rate changes. What is more, we suggest to study the heterogeneous impact of financial hoarding generated by different types of financial assets on economic growth in different economic environments, so as to promote the coordinated development of various markets, such as credit markets and capital markets, and study how to establish 
a multi-level, multi-channel investment and financing system and a diversified financial organization system.

Author Contributions: Conceptualization Y.F. and Z.S.; methodology Y.F. and Z.S.; validation Y.F. and Z.S.; formal analysis Y.F., Z.S. and Q.G.; investigation Y.F. and Z.S.; writing and editing Y.F., Z.S. and Q.G. All authors have read and agreed to the published version of the manuscript.

Funding: This research received no external funding.

Institutional Review Board Statement: Not applicable.

Informed Consent Statement: Not applicable.

Data Availability Statement: The data presented in this study are openly available in CEInt Statistics Database https:/ / db.cei.cn, accessed on 25 April 2020.

Conflicts of Interest: The authors declare no conflict of interest.

\section{References}

1. Wicksell, K. The influence of the rate of interest on prices. Econ. J. 1907, 17, 213-220. [CrossRef]

2. Binswanger, M. The finance process on a macroeconomic level from a flow perspective: A new interpretation of hoarding. Int. Rev. Financ. Anal. 1997, 6, 107-131. [CrossRef]

3. Andresen, T.A. Critique of a Post Keynesian model of hoarding, and an alternative model. J. Econ. Behav. Organ. 2006, 60, $230-251$. [CrossRef]

4. Nizam, R.; Karim, Z.A.; Rahman, A.A.; Sarmidi, T. Financial inclusiveness and economic growth: New evidence using a threshold regression analysis. Econ. Res. 2020, 33, 1465-1484. [CrossRef]

5. Rabail, A.I.; Muhammad, R.Y.; Rakhshanda, K.; Muhammad, U.; Muhammad, S.A.M. Impact of Trade Openness and Human Capital on Economic Growth: A Comparative Investigation of Asian Countries. Sustainability 2020, $12,2930$.

6. Liu, Y. Aging and economic growth: Is there a role for a two-child policy in China? Econ. Res. 2020, 33, 438-455. [CrossRef]

7. Zvonimira, S.G.; Marinela, K.N.; Elena, R. Circular Economy Concept in the Context of Economic Development in EU Countries. Sustainability 2020, 12, 3060.

8. Iuga, I.C.; Mihalciuc, A. Major Crises of the XXIst Century and Impact on Economic Growth. Sustainability 2020, 12, 9373. [CrossRef]

9. Wawrzyniak, D.; Doryn, W. Does the quality of institutions modify the economic growth-carbon dioxide emissions nexus? Evidence from a group of emerging and developing countries. Econ. Res. 2020, 33, 124-144. [CrossRef]

10. Romualdas, G.; Gitana, D.; Martin, S.; Kęstutis, P. The inter linkages between financial and economic development in the European Union Countries. Econ. Res. 2019, 32, 128-147.

11. Mohammad, E.H.; Low, S.W.; Mohd, A.S.Z. Oil price shocks, global economic policy uncertainty, geopolitical risk, and stock price in Malaysia: Factor augmented VAR approach. Econ. Res. 2019, 32, 3700-3732.

12. Cai, F. Special articles for the 60th establishment anniversary of economic research journal. Econ. Res. J. 2015, 12, 8-10.

13. Li, Y. Contention on finance serving the real economy. Econ. Res. J. 2017, 6, 4-16.

14. Zhu, C.; Du, C.; Zeng, F. The scale measurement and countermeasures in China's financial hoarding. South China Financ. 2016, 11, $11-15$.

15. Ren, Z. Financial hoarding and China's currency mystery. J. Chang. Financ. Coll. 2012, 3, 16-20.

16. Ma, Y.; Song, T. Circular flow of money and asset prices fluctuation. Financ. Econ. 2013, 9, 1-10.

17. Ma, Y.; Xu, Y. Shadow banking, money hoarding and macroeconomic effect of monetary policy shock: Analysis based on a DSGE model. Stud. Int. Financ. 2017, 8, 54-64.

18. Chen, Q.; Zhang, H. On the relationship between financial development and economic development from the perspective of polarization theory-A response to "financial cellar". Rev. Econ. Manag. 2018, 34, 114-129.

19. Berrospide, J.M. Bank Liquidity Hoarding and the Financial Crisis: An Empirical Evaluation. FEDS Working Paper No. 2013-03. 2013. Available online: https://papers.ssrn.com/sol3/papers.cfm?abstract_id=2207754 (accessed on 25 April 2020).

20. Aizenman, J.; Lee, J. Financial versus monetary mercantilism: Long-run view of large international reserves hoarding. World Econ. 2008, 31, 593-611. [CrossRef]

21. Lu, W.; Huang, J.; Musshoff, O. Climate threshold, financial hoarding and economic growth. Appl. Econ. 2015, 47, 4535-4548. [CrossRef]

22. Brossard, O.; Saroyan, S. Hoarding and short-squeezing in times of crisis: Evidence from the euro overnight money market. J. Int. Financ. Mark. 2016, 40, 163-185. [CrossRef]

23. Kang, S.; Hwang, I.; Song, S. Cash hoarding: Vice or virtue. J. Int. Financ. Mark. Inst. Money 2018, 53, 94-116. [CrossRef]

24. Ren, X. Money supply and the development of small and medium sized enterprises from the perspective of "financial hoard". Xinjiang Soc. Sci. 2019, 7, 31-39. 
25. Ren, X.; Bo, N. Performance, impact and measurement analysis of China's financial hoard. East China Econ. Manag. 2020, 34, 82-90.

26. Berger, A.N.; Guedhami, O.; Kim, H.H.; Li, X. Economic policy uncertainty and bank liquidity hoarding. J. Financ. Intermed. 2020, 100893. [CrossRef]

27. Aizenman, J.; Cheung, Y.; Ito, H. International reserves before and after the global crisis: Is there no end to hoarding? J. Int. Money Financ. 2015, 52, 102-126. [CrossRef]

28. Ashraf, B.N. Policy Uncertainty and Bank Liquidity Hoarding: International Evidence. 2020. Available online: https://ssrn.com/ abstract=3574193 (accessed on 25 April 2020). 